\title{
MICROSTRUCTURE, TRIBOLOGICAL BEHAVIOUR AND XRD ANALYSIS OF HVOF SPRAYED AND LASER REMELTED COCrTaAICSiY COATINGS
}

\author{
${ }^{1}$ GLANC Aleš, ${ }^{1}$ HOUDKOVÁ Šárka, ${ }^{1} J A N S A$ Zdeněk, ${ }^{1}$ VOSTŘÁK Marek \\ ${ }^{1}$ University of West Bohemia, New Technologies - Research Centre, Plzeň, Czech Republic, EU, \\ glancale@kmm.zcu.cz
}

https://doi.org/10.37904/metal.2020.3539

\begin{abstract}
Superalloys with cobalt as a base material are widely used among different industry applications. Their main advantages are excellent corrosion and wear resistance. Material CoCrTaAICSiY was chosen for this study as an unexplored representative of Co-based superalloys with a potential for good tribological behavior. This paper follows the results of previous paper called "Microstructure and Tribological Behavior of HVOF Sprayed and Laser Remelted CoCrTaAICSiY Coatings". In this paper are also presented three states of HVOF sprayed and post laser treated coatings of CoCrTaAICSiY (as spray state and two different laser treatments varying in specific energy of laser). Pin-on-disc test was carried out to evaluate wear behavior. XRD analysis was done to reveal phase transformations between FCC and HCP. A positive effect on wear coefficient for both laser treated CoCrTaAICSiY coatings was proved.
\end{abstract}

Keywords: HVOF, CoCrTaAICSiY, laser heat treatment, pin-on-disc, XRD

\section{INTRODUCTION}

Modern industry applications such as power generation, aerospace, chemical industry or medicine continuously increase its demands concerning increasing material properties. On the other hand there are tendencies to reduce total costs. Especially in applications where high corrosion and wear resistance is required, there is opportunity to meet new kinds of materials. Thermal spray technologies combine excellent material properties and simultaneously enable the reduction of manufacturing costs. A coating material with superior properties is applied on the surface of a component manufactured from common used and cheap material. There is a wide range of different methods of thermal spraying processes. Their usage varies according the feeding material, application of the coating, quality requirements, etc. One of widely used thermal spraying method is HVOF (High Velocity Oxygen Fuel Spraying). The HVOF coatings are generally characterizes by low porosity and high adhesion to substrate [1]. In certain applications could an additional heat treatment be beneficial for improving of material properties. It is also possible to apply heat treatment to HVOF coatings. Laser surface remelting (LSR) is one of modern heat treatment methods [2]. Application of laser heat treatment on thermal sprayed coatings could generally result in elimination of porosity and intersplat boundaries. Changes in microstructure depend on the amount of heat treatment and under specific conditions could lead to improvement of corrosion and wear resistance.

There exists a wide range of wear resistant materials which chemical composition could vary a lot. Composites of hard carbides with a metallic matrix are typical examples of the wear resistant material, such materials are often composed of chromium carbides $\mathrm{Cr}_{3} \mathrm{C}_{2}$ or tungsten carbides WC which are distributed in $\mathrm{Fe}$, $\mathrm{Co}$ or Nibased metallic matrix. Commonly used representatives of wear resistant composites are $\mathrm{Cr}_{3} \mathrm{C}_{2}-25 \mathrm{NiCr}$ [3], $\mathrm{Cr}_{3} \mathrm{C}_{2}-25 \mathrm{CoNiCrAIY}$ [4], WC-Co [5,6] and $\mathrm{WC}-\mathrm{Cr}_{3} \mathrm{C}_{2}-\mathrm{Ni}$ [7]. Another wear resistant group of materials are superalloys, which are well known but still not enough studied. Ni-based superalloys could be represented by 
NiCrBSi [8] or Hastelloy C-276 alloy which was researched previously [9]. Co-based superalloys could be represented by group of so called Stellites [10] with a typical example of Stellite 6 (CoCrWC alloy).

The material CoCrTaAICSiY is also Co-based superalloy with a high potential for wear resistance. Up to now, just a small attention was paid to this promising coating material The CoCrTaAICSiY is mainly manufactured as a powder for thermal spray coatings. Chromium (23-27 wt\%) is responsible for oxidation resistance, presence of tantalum (6.9-9.5 wt\%) could lead to formation of tantalum carbides TaC which are harder than carbides $\mathrm{Cr}_{3} \mathrm{C}_{2}$ and yttrium content up to $1 \mathrm{wt} \%$ within Co-based alloys can cause improvement of tribological behavior [11]. These characteristics stay behind the selection of CoCrTaAICSiY as a experimental material for wear resistant HVOF coatings of this paper. Target of this study is characterization of laser heat treated HVOF coatings of CoCrTaAICSiY superalloy. This study follows the results which were reported in [12] and supplements it with an additional tests and analyses. This paper offers evaluation of pin-on-disc wear test, EDX analysis and XRD analysis. To ensure comparability to previous paper [12] the same HVOF and laser parameters settings were selected.

\section{EXERIMENTAL PROCEDURES}

\subsection{Coatings preparation}

As a substrate for HVOF thermal spraying the grit blasted plates of common 11523 steel with the dimensions $200 \mathrm{~mm} \times 100 \mathrm{~mm} \times 10 \mathrm{~mm}$ were used. The $\mathrm{Al}_{2} \mathrm{O}_{3}$ powder $\mathrm{F} 22$ with a grain size 0.8-1 mm was used for grit blasting process. The HVOF thermal spraying process itself was carried out in VZÚ Plzeň s.r.o. by HP/HVOF JP5000 TAFA model 5220 spraying equipment. As a coating material, commercially available gas atomized powder FST 469.001 CoCrTaAICSiY from Amperit product line with nominal chemical composition of 23-27 wt\% $\mathrm{Cr}, 6.9-9.5 \mathrm{wt} \% \mathrm{Ta}, 6.5-8.5 \mathrm{wt} \% \mathrm{Al}, 0.6-0.9 \mathrm{wt} \% \mathrm{C}, 0.6-0.9 \mathrm{wt} \% \mathrm{Si}, 0.6-0.9 \mathrm{wt} \% \mathrm{Y}$ and balanced Co was used. As a carrying gas was used nitrogen which prevents melted CoCrTaAICSiY particles from increased oxidation.

The subsequent laser heat treatment of HVOF coatings was carried out in New Technologies Research Centre of University of West Bohemia by HPDD $4 \mathrm{~kW}$ laser Coherent HighLight ISL-4000L with wave length $808 \pm 10$ $\mathrm{nm}$. To prevent coating layers from cracks caused by high thermal gradient, the preheating up to $350^{\circ} \mathrm{C}$ was applied for all samples. Two different laser settings (LR1 and LR2) were applied on HVOF coatings, for the setting LR1 it was: power $1070 \mathrm{~W}$, specific energy $5.4 \mathrm{~J} / \mathrm{mm}^{2}$, traverse speed $16.7 \mathrm{~mm} / \mathrm{s}$ and spot size $12 \mathrm{~mm}$ $\mathrm{x} 1 \mathrm{~mm}$ and for the setting LR2 it was: power $1070 \mathrm{~W}$, specific energy $17.8 \mathrm{~J} / \mathrm{mm}^{2}$, traverse speed $5 \mathrm{~mm} / \mathrm{s}$ and spot size $12 \mathrm{~mm} \times 1 \mathrm{~mm}$.

\subsection{Coatings analyses}

For experimental procedures three kinds of CoCrTaAICSiY coating specimens were prepared: as-sprayed state of coating and two subsequently laser treated specimens (LR1 and LR2). Automated grinding and polishing equipment by Struers was used for grounding and polishing of the cross sections specimens according standard procedures for HVOF coatings. Microstructure of prepared specimens was observed with usage of scanning electron microscope EVO MA 25 from Carl Zeiss, equipped by EDX detector X-Max SDD from Oxford Instruments. Images from SEM were supplemented by points, lines and maps EDX analyses. Image analysis of SEM images was carried out in program ImageJ in order to evaluate amount of coatings porosity.

The XRD analysis was performed in New Technologies Research Centre of University of West Bohemia. The structure of the samples was observed by XRD using an automatic powder diffractometer X'Pert Panalytical Pro with $\mathrm{x}$-ray tube CuKa radiation $(\lambda=1.540598 \mathrm{~nm})$. XRD patterns were collected using symmetric geometry $\theta-\theta$ in the range of 30 to 100 degrees. The patterns were collected by ultra-fast semiconductor detector PIXcel 
with high resolution. ICDD database of powder diffraction patterns was used for evaluation of phase composition.

The tribology behavior of all tested specimens was evaluated by pin-on-disc wear test (ASTM G99-17) on the previously ground (ca. $0.04 \mathrm{Ra}$ ) and polished surfaces. As a testing equipment the tribometer CSEM from CSM Instruments was used and the parameters were as follows: $10 \mathrm{~N}$ normal force, corundum $\left(\mathrm{Al}_{2} \mathrm{O}_{3}\right)$ counterpart ( $6 \mathrm{~mm}$ diameter ball), $3.5 \mathrm{~mm}$ radius of sliding track, $10 \mathrm{~cm} / \mathrm{s}$ sliding speed, 5000 cycles and 110 $\mathrm{m}$ total sliding distance. The depths of sliding tracks were measured with usage of laser microscope OLS5000 from Olympus, then the total volume loss was calculated. Afterwards the sliding wear behavior at room temperature could be described by measured coefficient of friction (COF) and calculated wear coefficient (K).

\section{RESULTS AND DISCUSSION}

This study follows the results of previous paper [12] and adds new methods of analyses in order to understand tribological behavior and microstructure changes after laser heat treatment of HVOF sprayed CoCrTaAICSiY coatings.

\subsection{Microstructure}

For microstructure of HVOF as-sprayed CoCrTaAICSiY coatings (Figures $\mathbf{1 a}, \mathbf{1} \mathbf{b}$ ) is typical dense web of individual splats with small amount of porosity $(1.5 \pm 0.4 \%)$ which occur especially along the splat boundaries. White spots on Figure 1a were identified by EDX analysis as tantalum carbides TaC, their size is in the order of tens $\mu \mathrm{m}$. On the boundary between substrate and coating are occasionally visible particles of $\mathrm{Al}_{2} \mathrm{O}_{3}$ (Figures 1a, 1c) which were stuck in substrate after grit blasting.
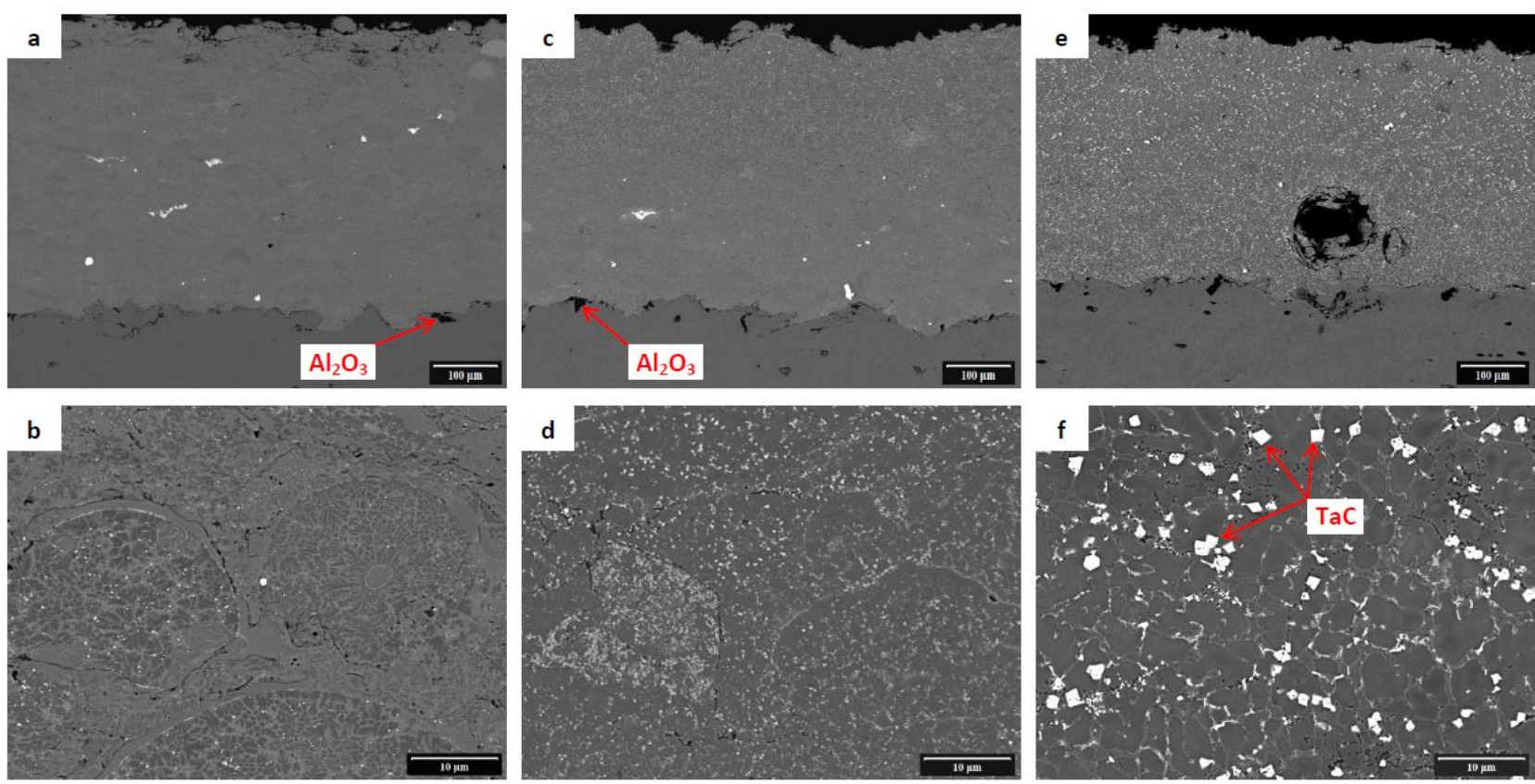

Figure 1 SEM of microstructure for HVOF sprayed CoCrTaAICSiY coatings:(a, b) as-sprayed, (c, d) laser treatment LR1, (e, f) laser treatment LR2

Microstructure of LR1 coating (Figures 1c, 1d) is partly recrystalized, the depth of heat treatment is roughly a third of coating thickness. In upper coating layer the intersplat boundaries completely vanished and porosity is generally lower $(0.7 \pm 0.1 \%)$ and typically concentrated to clusters. Heat treatment additionally lead to precipitation of very small TaC particles in heat affected zone. These $\mathrm{TaC}$ particles grow up toward the coating surface, their size is ca. 0.1-1 $\mu \mathrm{m}$. Laser parameters LR2 resulted in heat treatment of complete coating 
thickness (Figures 1e, 1f), it was also confirmed by EDX analysis which shows dilution of Fe from substrate into coating material. Final coating is more compact and homogenous than as-spayed coating. Porosity $(0.5 \pm$ $0.1 \%$ ) is the lowest from the measured specimens. The TaC precipitation continued and size of such $\mathrm{TaC}$ particles increased in comparison to LR1 coating up to several $\mu \mathrm{m}$ in the top coating layer. Microstructure of LR2 coating is characterized by zones (Figure 1f) which are rich on $\mathrm{Co}$ and $\mathrm{Al}$, and areas among them are on the other hand rich in $\mathrm{Cr}$, Ta and $\mathrm{Si}$ and these Ta rich areas serve as a place for $\mathrm{TaC}$ nucleation. EDX analysis (Figure 2) revealed chemical composition of coatings microstructure.

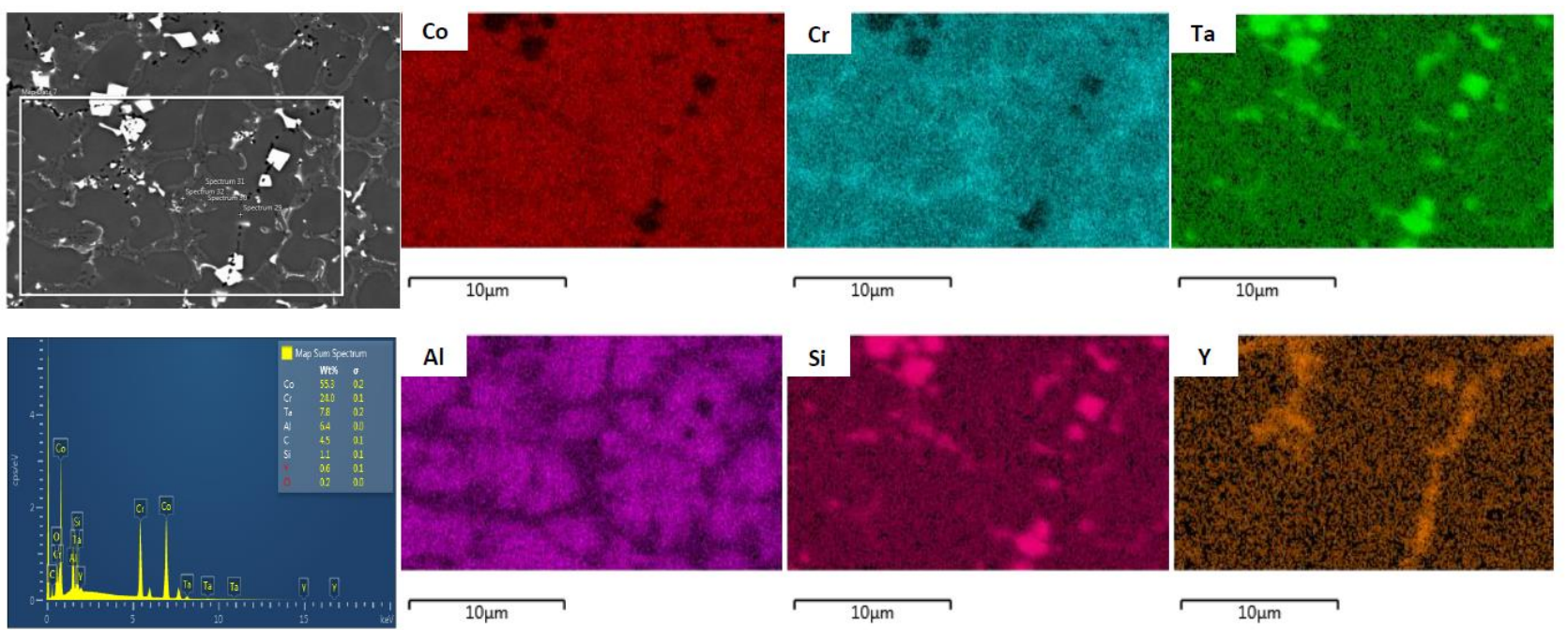

Figure 2 EDX analysis of HVOF sprayed CoCrTaAICSiY coating with laser treatment LR2

\subsection{XRD analysis}

The XRD analysis reveal the phase composition of all tested specimens. The results are shown as volume fractions in Table 1.

Table 1 Volume fractions of individual phases obtained from XRD analysis of HVOF sprayed CoCrTaAICSiY coatings

\begin{tabular}{|c|c|c|c|c|c|c|c|c|}
\hline \multirow{2}{*}{ Specimen } & \multicolumn{8}{|c|}{$\begin{array}{c}\text { Phase composition } \\
\text { (vol\%) }\end{array}$} \\
\hline & $\begin{array}{l}\mathrm{Co}_{2.00} \\
(\mathrm{HCP})\end{array}$ & $\begin{array}{c}\mathrm{TaC} / \mathrm{TaO} \\
\text { (FCC) }\end{array}$ & $\begin{array}{l}\mathrm{CoSi}_{2} \\
\text { (FCC) }\end{array}$ & $\begin{array}{c}\mathrm{Cr} \\
(\mathrm{BCC})\end{array}$ & $\begin{array}{c}\mathrm{Al}_{80} \mathrm{Cr}_{20} \\
\text { (icosahedral) }\end{array}$ & $\begin{array}{c}\mathrm{Cr}_{0.9} \mathrm{Si}_{0.1} \\
\text { (BCC) }\end{array}$ & $\begin{array}{c}\mathrm{Cr}_{0.1} \mathrm{Ta}_{0.9} \mathrm{C} \\
\text { (FCC) }\end{array}$ & $\begin{array}{c}\mathrm{Y}_{3} \mathrm{Al}_{5} \mathrm{O}_{12} \\
\text { (cubic) }\end{array}$ \\
\hline as-sprayed & 56.43 & 15.16 & 9.47 & 18.94 & 0 & 0 & 0 & 0 \\
\hline LR1 & 37.67 & 24.31 & 0 & 0 & 6.13 & 31.89 & 0 & 0 \\
\hline LR2 & 21.34 & 17.00 & 0 & 0 & 0 & 29.18 & 15.71 & 16.77 \\
\hline
\end{tabular}

From Table 1 is evident that the dominant phase of $\mathrm{CoCrTaAICSiY}$ as-sprayed coating is $\mathrm{Co}_{2.00}$ with hexagonal close-packed (HCP) structure. Additionally, there is certain amount of $\mathrm{Cr}$ and $\mathrm{CoSi}_{2}$. The $\mathrm{TaC}$ and $\mathrm{TaO}$ have face-centered cubic (FCC) structure and they are in Table 1 listed as one phase because of very close diffraction lines. E.g. for the strongest diffraction line (111) is the difference $0.057^{\circ} 2 \theta$ and the difference in lattice parameters is at fourth decimal number ( $\mathrm{TaC}$ has $0.4447 \mathrm{~nm}$ and $\mathrm{TaO}$ has $0.4440 \mathrm{~nm}$ ). For as-sprayed coating can be assumed that this phase composes almost exclusively from $\mathrm{TaC}$ because of nitrogen shrouding during HVOF deposition. The laser heat treatment of LR1 specimen lead to transformation of originally dominant $\mathrm{Co}_{2.00}$ phase to bigger amount of $\mathrm{TaC} / \mathrm{TaO}$ phase and to body-centered cubic $(\mathrm{BCC}) \mathrm{Cr}_{0.9} \mathrm{Si}$ o.1 phase . 
Laser heat treatment with higher specific energy (LR2) lead to continued reduction of original HCP phase of $\mathrm{Co}_{2.00}$ and on the other hand, begin to appear more complex carbides $\left(\mathrm{Cr}_{0.1} \mathrm{Ta}_{0.9} \mathrm{C}\right)$ and oxides $\left(\mathrm{Y}_{3} \mathrm{Al}_{5} \mathrm{O}_{12}\right)$.

\subsection{Pin-on-disc test}

Evaluation of pin-on-disc wear test (ASTM G99-17) is shown in graphs in Figure 3 and Figure 4. Coefficient of friction (COF) recorded during complete duration of pin-on-disc test reveal slightly increasing gradient for all tested specimens. Main wear mechanism of all specimens is abrasion. Both laser treated parameters (LR1 and LR2) show similar COF which is ca. $15 \%$ lower that COF of as-sprayed coating. It could be explained by vanishing of intersplat boundaries in heat affected zone which prevents from delamination of individual splats during pin-on-disc test. Laser heat treatment positively affected wear coefficient $(K)$. It is more obvious for LR2 specimen. This reduction of $\mathrm{K}$ is most likely due to precipitation of hard $\mathrm{TaC}$ particles in heat affected zone.

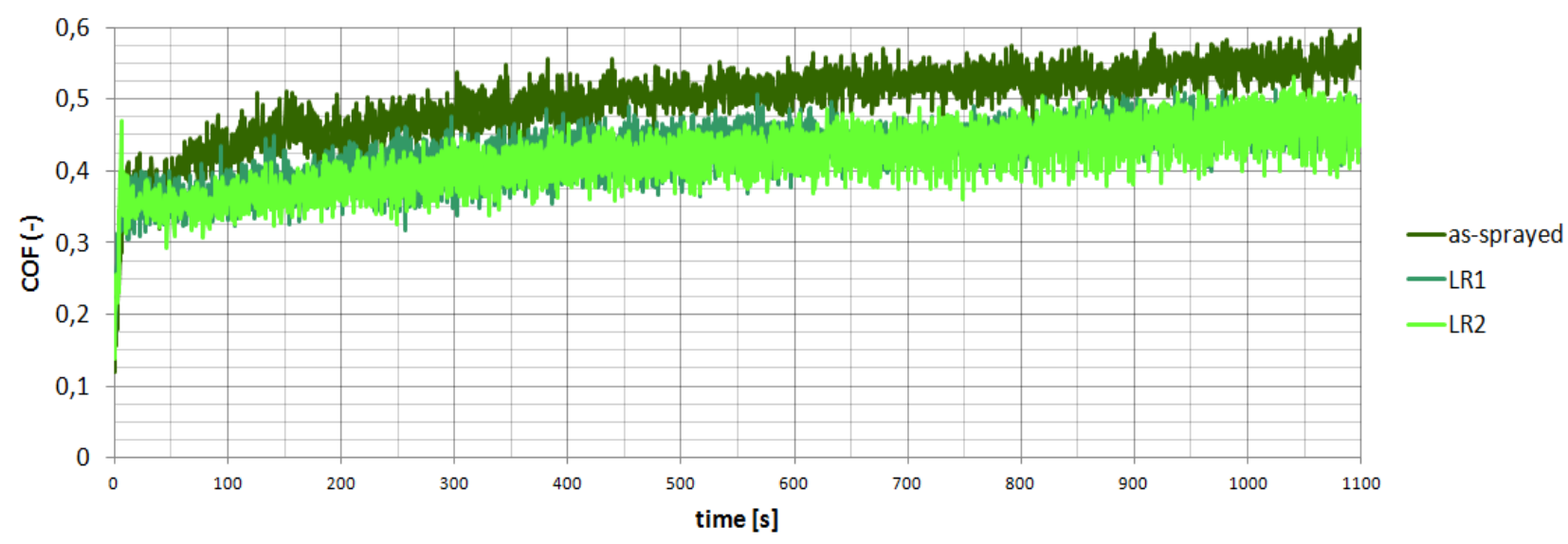

Figure 3 Coefficient of friction (COF) recorded during complete pin-on-disc wear test
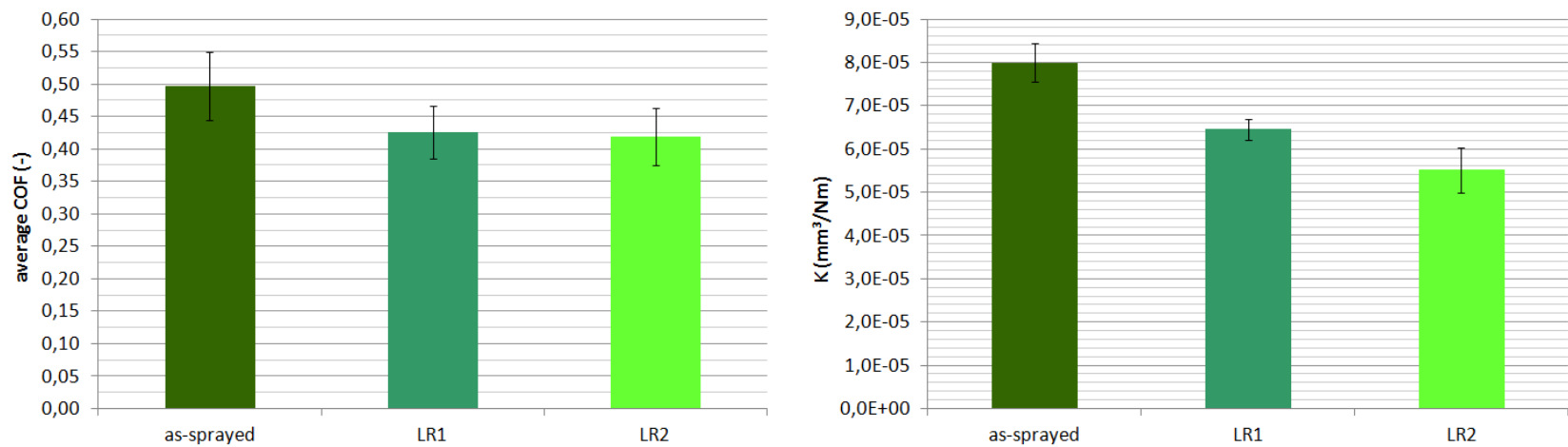

Figure 4 Average coefficient of friction (COF) and wear coefficient (K) evaluated from pin-on-disc wear test

\section{CONCLUSION}

This paper is focused on evaluation of laser heat treatment applied on the HVOF sprayed coatings of CoCrTaAICSiY. Results of pin-on-disc wear test, SEM with EDX analysis and XRD analysis which are listed in this study complement wear and erosion tests reported in previous study [12]. The pin-on-disc test confirmed positive effect of laser heat treatment on COF and $\mathrm{K}$ which are in good agreement with results of linearly oscillating ball-on-flat wear test (ASTM G-133). Improved wear behavior of laser treated specimens is caused by several factors. Firstly, is there a certain effect from microhardness changes related to vanishing of porosity. Second more dominant factor is presence of hard TaC particles which were confirmed by EDX and XRD analyses. Images from SEM reveal that $\mathrm{TaC}$ particles are growing with increasing laser heat treatment. TaC 
hard particles serve as a obstacle during abrasion thus increasing wear resistance of CoCrTaAICSiY coating is more evident for LR2 specimen with higher specific energy of laser.

\section{ACKNOWLEDGEMENTS}

\section{The research outcome was developed within the project SGS-2016-005.}

\section{REFERENCES}

[1] OKSA, M., TURUNEN, E., SUHONEN, T., VARIS, T., HANNULA, S.P. Optimization and Characterization of High Velocity Oxy-fuel Sprayed Coatings: Techniques, Materials, and Applications. Coatings, 2011, vol. 1, no. 1, pp. 17-52.

[2] BUCHFINK, G. The Laser as a Tool. Germany - Würzburg: Vogel Buchverlag, 2007.

[3] BAEZ, I.L., SALAS, C.A.P., SALDANA, J.M., MARTINEZ, L..T. Effects of the Modification of Processing Parameters on Mechanical Properties of HVOF Cr3C2-25NiCr Coating. Journal of Thermal Spray Technology, 2015, vol. 24, no. 6, pp. 938-946.

[4] PICAS, J.A., PUNSET, M., MENARGUES, E., MARTIN, E., BAILE, M.T. Microstructural and Tribological Studies of As-sprayed and Heat-treated HVOF Cr3C2-CoNiCrAlY Coatings with a CoNiCrAlY Bond Coat. Surface and Coatings Technology, 2015, vol. 268, pp. 317-324.

[5] WOOD, R.J.K. Tribology of Thermal Sprayed WC-Co Coatings. International Journal of Refractory Metals and Hard Materials, 2010, vol. 28, no. 1, pp. 82-94.

[6] GENG, Z., LI, S., DUAN, D.L., LIU, Y. Wear Behaviour of WC-Co HVOF Coatings at Different Temperatures in Air and Argon. Wear, 2015, vol. 330-331, pp. 348-353.

[7] ZHANG, S.H., CHO, T.Y., YOON, J.H., LI, M.X., SHUM, P.W., KWON, S.C. Investigation on Microstructure, Surface Properties and Anti-Wear Performance of HVOF Sprayed WC-CrC-Ni Coatings Modified by Laser Heat Treatment. Materials Science and Engineering B, 2009, vol. 162, pp. 127-134.

[8] SERRES, N., HLAWKA, F., COSTIL, S., LANGLADE, C., MACHI, F. An Investigation of the Mechanical Properties and Wear Resistance of NiCrBSi Coatings Carried out by in situ Laser Remelting. Wear, 2011, vol. 270, pp. 640-649.

[9] GLANC, A., HOUDKOVÁ, Š., VOSTŘÁK, M., BYSTRIANSKY, M. Microstructure and Tribological Behavior of HVOF Sprayed and Laser Remelted Hastelloy C-276 Coating. In METAL 2018: 27th International Conference on Metallurgy and Materials. Ostrava: TANGER, 2018, pp. 1121-1126.

[10] SASSATELLI, P., BOLELLI, G., GUALTIERI, M.L., HEINONEN, E., HONKANEN, M., LUSVARGHI, L., MANFREDINI, T., RIGON, R., VIPPOLA, M. Properties of HVOF-Sprayed Stellite-6 Coatings. Surface \& Coatings Technology, 2018, vol. 338, pp. 45-62.

[11] FARNIA, A., GHAINI, F.M., RAO, J.C., OCELÍK, V., HOSSON, J.Th.M. Effect of Ta on the Microstructure and hardness of Stellite 6 Coating Deposited by Low Power Pulse Laser Treatments. Surface and Coatings Technology, 2012, vol. 213, pp. 278-284.

[12] GLANC, A., HOUDKOVÁ, Š., VOSTŘÁK, M. Microstructure and Tribological Behavior of HVOF Sprayed and Laser Treated CoCrTaAICSiY Coatings. IOP Conference Series: Materials Science and Engineering, 2018, vol. 461 , no. $1,6 \mathrm{pp}$. 